\title{
信息化在农产品加工机械中的应用探讨
}

\author{
杨旭星 \\ 甘肃省轻工研究院有限公司 \\ DOI:10.32629/as.v2i6.1724
}

[ 摘 要] 农产品加工机械设备不仅是农产品加工和加工业的重要物质手段, 也是农业机械化的重要组成部分, 发展农产品初加工机械化能增加 农产品附加值, 促进农民就业增收。近年来, 由于纳入农机购置补贴目录的农产品初加工机械种类和范围的扩大, 以及补贴资金额度的增加。基 于此,文章就信息化在农产品加工机械中的应用进行了探讨。

[关键词] 农产品加工; 机械; 信息化; 建设; 发展

\section{1 农产品加工机械信息化概述}

农产品加工机械是指把各类农产品加工成供直接消费的成品、生产用 的种子和工业原料的机械设备, 广义的农产品加工机械还包括加工各种畜 产品、林产品和水产品的机械与设备。目前, 我国大力发展的农产品加工 机械有8类: 粮食加工机械, 油料加工机械, 果品加工机械, 茶叶加工机械, 棉花加工机械, 淀粉加工机械, 混合饲料加工机械, 蚕茧、橡胶等经济价值 较高的农产品加工机械。

信息化是指以现代通信、网络、数据库技术为基础, 对所研究对象各 要素汇总至数据库, 供特定人群生活、工作、学习、辅助决策等和人类息 息相关的各种行为相结合的一种技术。

农产品加工机械的信息化则是将信息化技术应用到农产品加工机械 的设计、生产、使用、维护中, 以提升农产品加工机械的设计制造水平, 改善农产品加工机械的工作运行效率, 推进农产品加工机械的现代化发展 进程。

\section{2 农产品加工机械应用信息化的重要性}

2. 1 农产品加工信息化建设可以极大地促进我国农业的发展进程

农产品加工业需要加大其对农产品加工转化的能力, 能够做到及时吸 收和转化相关产品, 达到延长产业链的作用。通过增加农产品的技术含量 和附加值, 就可以更好地从社会和经济发展中发现影响农产品的各种关键 因素。通过科技手段预测农产品的质量和产量, 提前做好加工产业的生产 准备, 在农产品收获季节, 根据产品的真实产量调整相关的生产计划和营 销策略。要想实现农产品加工产业的快速发展, 就必须采用现代信息化手 段, 建立反应敏捷的信息系统, 可以帮助基础农业加快向加工业迅速靠拢。 通过获取市场需求量、产品的市场前景、发展趋势等重要信息, 也对农产 品加工业实现信息化提出了客观要求。

\section{2 信息化建设可以帮助农产品加工业实现高标准发展}

农产品加工业要想实现高标准发展, 首先应当实现农产品加工机械的 信息化。通过分析研究国内外市场, 树立全新的加工理念, 以顾客需求为中 心, 实行现代化的信息收集、产品生产、经营营销等全方面的信息化建设。 采用现代化的加工机械, 注重农产品生产设备的更新换代, 使用现代的计 算机技术、网络通信技术等信息技术, 研究开发市场, 为实现农产品加工业 的高标准发展奠定基础。通过科技研究加大信息化技术在农产品加工业中 的应用, 是促进农产品加工业发展的重要方式。

3 信息化在农产品加工机械中的应用

3. 1 信息化在农产品加工机械设计中的应用
信息化在农产品加工机械设计中的应用主要体现在计算机辅助设计。 农产品加工机械设计的初期, 通常需要对不同方案进行大量的计算、分析 和比较, 以决定最优方案。通过计算机辅助, 设计人员可以快速地对数据进 行检索和处理, 以提升工作效率。此外, 借助计算机的图形处理能力, 设计 人员也可以更方便和精确地对设计图进行修改、缩放、平移、旋转等编辑 工作, 提升设计效率和质量。

\section{2 信息化在农产品加工机械使用中的应用}

信息化在农产品加工机械使用中的应用多不胜数, 最典型的莫过于人 机界面技术的使用。人机界面就是人与机械设备进行交互的操作方式和传 递信息 (包括输入信息和输出信息) 的媒介。例如, 带有触控功能的液晶显 示屏, 这一高科技设备同时具备了信息的输入和输出功能, 不仅能够直观 地将农产品加工机械的运行状态、工作参数等数据显示出来, 还可以很方 便的供设备使用人员进行各种操作, 以调节设备的工作参数, 提升农产品 加工机械的工作效率。

3. 3信息化在农产品加工机械管理中的应用

随着农产品加工机械的大规模投入使用, 越来越多的农产品加工机械 也对设备的管理维护提出了新的挑战, 农产品加工机械管理的信息化建设 也越发显得重要。通过建立完备的农产品加工机械信息库, 详细储存机械 设备的技术参数、性能指标、寿命周期等信息, 机械设备的保养维修、配 件更换, 燃油消耗等记录, 并在此基础上进行一定的数据分析和预测, 不仅 可以帮助机械使用者更加合理的购置、调配和利用设备, 还可以有效降低 使用成本、延长使用寿命。

\section{4 结语}

总之, 农产品加工业是促进农民就业增收的重要渠道, 是建设现代农 业的重要内容和农村经济发展的重要支柱, 因此, 应当加速农产品加工机 械的发展进程, 结合信息化技术, 大力发展和利用农产品加工技术, 扩大农 产品的深加工, 增加农产品的附加值, 提高农产品资源的利用效率, 实现农 产品加工机械的现代化发展。

[参考文献]

[1]彭自力.农产品加工机械化信息化发展概述[J].电脑迷,2018,(07):221.

[2]张驰. 农产品透明供应链关键技术及其应用研究 [D]. 中国农业大 学,2017,(07):124.

[3]张驰, 张晓东, 王登位.消费者参与模式下的农产品透明供应链系统 研究[J].中国农学通报,2017,33(07):158-164. 